Portland State University

PDXScholar

\title{
Ethics, Equity, and English-Language Learners: A Decision-Making Framework
}

Shelly Chabon

Portland State University

Julie Esparza Brown

Portland State University, jebrown@pdx.edu

Christina E. Gildersleeve-Neumann

Portland State University, cegn@pdx.edu

Follow this and additional works at: https://pdxscholar.library.pdx.edu/edu_fac

Part of the Bilingual, Multilingual, and Multicultural Education Commons, Educational Methods Commons, and the Speech and Hearing Science Commons Let us know how access to this document benefits you.

\section{Citation Details}

Chabon, Shelly; Brown, Julie Esparza; and Gildersleeve-Neumann, Christina E., "Ethics, Equity, and EnglishLanguage Learners: A Decision-Making Framework" (2010). Education Faculty Publications and Presentations. 84.

https://pdxscholar.library.pdx.edu/edu_fac/84

This Post-Print is brought to you for free and open access. It has been accepted for inclusion in Education Faculty Publications and Presentations by an authorized administrator of PDXScholar. Please contact us if we can make this document more accessible: pdxscholar@pdx.edu. 


\title{
8-3 chabon ethics and ELL early intervention
}

\section{Raising Ethical Questions about Early Intervention with ELLs: In Search of a Just Balance}

\author{
by Shelly Chabon, Julie Esparza Brown, and Christina Gildersleeve-Neumann
}

Speech-language pathologists and audiologists always strive to identify and implement the most ethical and appropriate services. However, clinical decision-making in early intervention with English-language learners and their families can be especially challenging as it is usually complicated by the personal, institutional, and societal interests of the individuals involved.

There are key ethical questions in the assessment of and intervention for preschool children who are English-language learners (ELLs). Some of these questions have been studied and others have yet to be examined, but all deserve further deliberation as their answers reflect multiple perspectives and an ever-changing body of evidence. An equitable, consensus-building decision-making process is important to accommodate the perspective of the family, the service provider and those of the children served. In this article, we present a process for addressing these ethical questions.

Current practices in speech-language pathology support decision-making that honors each family's priorities in identifying assessment and treatment options. Consideration is typically given to the full range of acceptable actions and in particular, whether they are (1) obligatory or necessary, (2) impermissible or never appropriate under any circumstance, or (3) permissible with the potential for positive outcomes. The benefits and burdens of each identified action are then thoroughly explored within the contexts of the individual and the community (Chabon \& Morris, 2004).

When faced with an ethical question about ELLs, it is important to examine the relevant evidence and clinical expertise, as well as the perspectives, value, and beliefs of the individuals involved, and to evaluate this information in relation to the ASHA Code of Ethics (ASHA, 2005). A systematic approach based in part on the organizational framework described by Chabon and Morris (2004) can be applied to address ethical dilemmas. The framework includes a series of questions for clinicians to ask in arriving at a decision:

- What is the ethical question?

- What do we know?

- What do we need to know?

- Who are the people involved?

- What are the possible actions?

- What evidence, legal and ethical guidance, and/or personal, social, and professional insights support/contradict this action? 
Implementing the framework is demonstrated by the following scenario:

Rosita is 3 years, 8 months old. She came to the United States from Mexico six months ago with her parents and 1-year-old brother. Spanish is the language used at home. For the past five months she has attended a head-start preschool where only a few staff-one teacher, one teaching assistant, the cooking staff, and an assistant director-speak Spanish. Many of the children who attend the school are also native Spanishspeakers. Three months after Rosita entered preschool, her teacher referred her for a speech and language assessment. The SLP, who speaks only English, is in her first year at this preschool. She recently completed her clinical fellowship (CF) at a neighborhood school, and her mentor has moved out of state. The preschool director, also a monolingual English speaker, spent most of his long career at a suburban elementary school where most students spoke only English. The SLP knows that she should not proceed with the evaluation without an interpreter. The preschool is using the teaching assistant, whose son attends the preschool, to assist with language translation as needed. Unfortunately, she is not a trained interpreter and is also not comfortable with her own English skills. The SLP has taken her concerns to the preschool director, who although sympathetic to the situation, is fairly insistent that the SLP complete the evaluation.

\section{What is the ethical question?}

Is it obligatory, permissible, or impermissible for a monolingual SLP to conduct an evaluation of a child whose first language is not English?

\section{What do we know?}

The relevant facts include the girl's age; family situation; length of time in the United States; languages heard/spoken (at home and school); and where, when, and for how long she attended preschool. She was referred for a speech and language evaluation three months after she began preschool; the SLP is new to her position, recently completed a $\mathrm{CF}$, and is a monolingual speaker. The SLP's supervisor, also a monolingual speaker, has had a long career but is new to this setting; a teaching assistant, who has a child attending the preschool, has been serving as an interpreter.

\section{What do we need to know?}

It would be helpful to know:

- More about the child and parents’ proficiency in both languages and their previous experience with the languages at home and elsewhere.

- Other key individuals in the child's sphere of influence (caretakers, extended family) and the languages that they speak. This background information helps assess the child's current and future need for both Spanish and English.

- Why the teacher made this referral and whether the parents have concerns about the child's communication skills. 
- What resources are available in the community and school to assist this family and the SLP.

- The family's social support network and other relevant information.

\section{Who are the people involved?}

This situation includes many stakeholders, including Rosita, her brother, and their parents; the SLP; the preschool director and classroom teacher; the teaching assistant; and the other children attending the school. Other SLPs, educators, and staff members employed at the school and elsewhere also could be indirectly affected by the decision because services in one setting or facility can be interpreted by some to reflect standard or best practice.

\section{What are the possible actions?}

Assuming that consultation with the parents and teacher and observations of the child confirm the need for an evaluation, there are a number of possible responses to this ethical question. It is important to emphasize, however, that some actions are obligatory, some are permissible, and some are impermissible. The monolingual SLP could:

- Refuse to evaluate the child.

- Conduct the evaluation in English.

- Conduct the evaluation with the support of a bilingual speaker.

- Conduct the evaluation with the support of a trained interpreter.

- Arrange for a bilingual SLP to participate in or conduct the evaluation.

What evidence, legal and ethical guidance, and/or personal, social, and professional insights support/contradict each action?

Ethical \& Legal Guidance

A significant percentage of SLPs are either monolingual or not proficient enough in languages other than English to provide services to students who are bilingual (Caesar \& Kohler, 2007). The guidance from the ASHA Code of Ethics (specifically Principles of Ethics I, Rules A and B) prescribes that services be provided competently with all available resources, including referral when appropriate (ASHA, 2010). Principle of Ethics 1, Rule C, prohibits discrimination on the basis of race or ethnicity, a provision that would eliminate the option of refusing to treat this child without ensuring that she received proper services.

This provision is further specified in an Issues in Ethics Statement on Cultural Competence, which notes, "When a clinician is not proficient in the language used by the client and family, a suitable interpreter [should] be used" (ASHA, 2005). Importantly, it also states, "Bilingual skill (understanding and speaking the language) does not equate to bicultural skill (understanding and respecting the culture)," and that both of these skills are required for service to be culturally competent.

The need to consider a child's native language in assessment is clearly mandated in the Individuals with Disabilities Education Improvement Action (IDEA, 2004). This reauthorization strengthened the language regarding equitable assessment. It states in part: 
Procedures to ensure that testing and evaluation materials and procedures utilized for the purposes of evaluation and placement of children with disabilities for services under this title will be selected and administered so as not to be racially or culturally discriminatory. Such materials or procedures shall be provided and administered in the child's native language or mode of communication, unless it is clearly not feasible to do so, and no single procedure shall be the sole criterion for determining an appropriate educational program for a child. (20 U.S.C. §1412 (6)(B))

\section{Research Evidence}

Spinelli (2008), citing several earlier studies, asserts that an evaluator should speak the language of the student, assess in both English and in the student's native language, and use an interpreter to assist in the test administration as needed. However, there is a shortage of bilingual SLPs who can assess children in both their native languages and English. There are, however, several steps described in the literature to guide SLPs in their equitable evaluations of preschool ELLs (Crowley, 2006; Flanagan, Ortiz, \& Alfonso, 2007): They need to know how culture and language affect assessment and intervention; they can use trained interpreters/translators to communicate in the child's native language; and they can request the assistance of a bilingual SLP.

Ortiz (2006) writes "Linguistic competence is reflected in two distinct ways: the ability to communicate effectively in an individual's native language (eliminating the need for an interpreter) and possession of a knowledge base related to first- and second-language development and instruction methodology and pedagogy.” Therefore, although the ability to speak a child's native language is desirable, it may not be necessary for equitable assessment if the SLP knows how the languages contrast, understands the issues involved in bilingual assessment, and uses skilled interpreters.

\section{Family's Priorities}

With the advent of P.L.94-142 (now IDEA) in 1975, parent participation has become central to the provision of early intervention services. Nonetheless, it has been difficult for service providers to shift from a tradition in which the professional provides the information, makes decisions, and then shares the information with parents to a practice that involves reciprocal planning, dialogue, and informed consent (DeGangi et al., 1994; Gutierrez \& Sameroff, 1990; Lieberman, 1990). Non-English-speaking parents often are provided with lengthy documents written in English that contain the Procedural Safeguards that outline their rights. Fitzgerald and Watkins (2006) reviewed parental rights documents from 50 states and reported that 20\%-50\% were written at a college reading level or higher. Thus, even when this information is provided in their native language, it is often too difficult and complex for non-English speaking parents to comprehend.

This problem may be further exacerbated by conflicting visions of and expectations for the child, predetermined decisions about best placements, and other inexcusable events, such as interpreters who leave Individual Family Service Plan meetings before they are 
finished (S. Ramirez, personal communication, May 24, 2010). One educator who met with parents from an early intervention program summarized the parents' frustration as follows, "They don't know their children's rights beyond the limited therapies they have received” (S. Ramirez, personal communication, May 24, 2010).

Culturally responsive and ethically responsible intervention capitalizes on a child and family's experiences, knowledge, and values. All too often, however, children and families are asked to trade familiar behaviors and language patterns for those belonging to the mainstream culture to access services.

\section{Personal and Professional Insights}

ASHA policy states - and we are convinced from our collective experiences - that early intervention and assessment must focus on a child's abilities in both languages and be aligned with a family's expectations, values, and goals. Equitable assessment requires information regarding a child's level of proficiency in English and the native language, and the skills required by the tests used. A clinician, whether monolingual or bilingual, must ensure that assessment includes multiple sources of information in accordance with the parameters described above.

What are the consequences that may arise from each action?

Failure to conduct the assessment may have negative ramifications for the child if she is truly struggling with one or both languages, as well as for the clinician who might be viewed as insubordinate for refusing to comply with the employer's request. Conducting the evaluation in English only or in Spanish by an untrained Spanish "interpreter" may lead to the wrong diagnosis. If the child receives unnecessary services she may be labeled inappropriately and may take the place of someone who truly needs this intervention, creating false concerns for the child and family.

\section{Decision}

Through the evaluation of the law and the ethical principles involved, it is clear that it is impermissible for the SLP to refuse to evaluate the child, to evaluate the child in English only, or to evaluate this child without appropriate support. The SLP is obligated to provide culturally appropriate services and to educate fellow staff members about their need to conduct evaluations in both languages. Given the linguistic background of the children at the preschool, the SLP might consider reasonable options available to improve her own preparation for working with other non-English speaking children in the future.

\section{Future Challenges}

This example illustrates the application of a systematic approach to ethical decisionmaking. This process can be used to determine whether it would be obligatory, permissible, or impermissible for SLPs to:

- Address the many educational disparities that exist in providing services to ELLs. This would account for ease of access, availability of services, resources or lack thereof, lack of information due to potential language barriers, perceptions about eligibility (or ineligibility) for services, and lack of bilingual service providers. 
- Over-identify, over-diagnose, or misdiagnose communication disorders in ELLs.

- Under-identify, or adhere to a "waiting until they fail" philosophy in work with ELLs.

- Use, fail to use, and/or misuse interpreters with families of ELLs.

- Treat bilingual children when the SLPs are monolingual.

- Hire a bilingual SLP primarily or exclusively because of his or her language background and with limited consideration of other knowledge and skills.

- Offer training programs to prospective SLPs and other service providers that include little or no information about working with bilingual children.

- Use a non-SLP to assist with service delivery because he or she speaks the child's language.

- Deny children a response-to-intervention alternative because this service model does not receive special education funds.

- Use research evidence collected primarily on monolingual children to support practice decisions with bilingual children.

- Work with children who come from families with illegal status (this question may account for issues related to barrier-to-access and need-to-report).

- Teach English versus facilitate language development.

- Recognize the need to teach in the language of instruction. (Is the language of instruction in early intervention the language used in the home; why is the language of instruction given priority over the family language?)

- Refer bilingual preschoolers to a preschool where it is unlikely that they will interact with bilingual teachers, assistants, or children.

Though difficult, these questions cannot be avoided, nor should they be. It is in the pursuit of their resolution that we are reminded of our responsibilities and priorities in working with ELL children and their families.

As illustrated by the scenario, a number of variables and mitigating factors may influence responses to these queries and ultimately influence decisions. These include the language proficiency of the child and other family members, length of residence in the United State, presence of abilities and disabilities, level of support, generational differences, and educational background.

We hope that raising these questions and providing an example of a decision-making process will assist in the search for answers and the goal of engaging in best practices when faced with stakeholders - who speak different languages and may have different cultural values-who confront ethical challenges. We do believe, however, that the way we answer these questions and the decisions we make are evidence of our commitment to those we serve, and ultimately will inform our ethics, refine our science, and enhance our practices.

Shelly Chabon, PhD, CCC-SLP, is a professor in the Department of Speech and Hearing Sciences at Portland State University. Her research interests include ?????Contact her atchabonr@pdx.edu. 
Julie Esparza Brown, EdD, is an assistant professor in special education at Portland State University. For the past 12 years, much of her focus has been on preparing ESL and bilingual teachers and most recently, bilingual special educators. Contact her at jebrown@pdx.edu.

Christina Gildersleeve-Neumann, PhD, CCC-SLP, is an associate professor at Portland State University. She teaches and conducts research on speech sound development and disorders in children from a variety of cultural and linguistic backgrounds. Her current research explores treatment efficacy for Spanish-English bilingual children with speech sound disorders. Contact her at cgilders@pdx.edu.

\section{Acknowledgements}

We would like to acknowledge the wonderful SLPs in our Oregon Bilingual SLP group, from whose own questions and ideas this article was inspired.

\section{References:}

Caesar, L. G., \& Kohler, P. D. (2007). The state of school-based bilingual assessment: Actual practice versus recommended guidelines. Language, Speech and Hearing Services in Schools, 38, 190-200.

Chabon, S., \& Morris, J. (2004, Feb. 17). A consensus model for making ethical decisions in a less-than-ideal world. The ASHA Leader.

Crowley, C. J. (2006). Ethical issues and solutions: Working with English language learner students. Rockville, MD: ASHA.

Flanagan, D. P., Ortiz, S. O., \& Alfonso, V. C. (2007). Essentials of cross battery assessment ( $2^{\text {nd }}$ ed.). New York: Wiley.

American Speech-Language-Hearing Association. (2005). Evidence-Based Practice in Communication Disorders [Position Statement]. Available from www.asha.org/policy.

American Speech-Language-Hearing Association. (2008). Roles and Responsibilities of Speech-Language Pathologists in Early Intervention: Position Statement [Position statement]. Available from www.asha.org/policy.

American Speech-Language-Hearing Association. (2008). Roles and Responsibilities of Speech-Language Pathologists in Early Intervention: Guidelines [Guidelines]. Available from www.asha.org/policy.

American Speech-Language-Hearing Association. (2004). Preferred Practice Patterns for the Profession of Speech-Language Pathology [Preferred Practice Patterns]. Available from www.asha.org/policy. 